\title{
A call for innovative social media research in the field of augmentative and alternative communication
}

\section{Bronwyn Hemsley, Susan Balandin, Stuart Palmer \& Stephen Dann}

To cite this article: Bronwyn Hemsley, Susan Balandin, Stuart Palmer \& Stephen Dann (2017) A call for innovative social media research in the field of augmentative and alternative communication, Augmentative and Alternative Communication, 33:1, 14-22, DOI: 10.1080/07434618.2016.1273386

To link to this article: http://dx.doi.org/10.1080/07434618.2016.1273386

\section{曲 Published online: 25 Jan 2017.}

Submit your article to this journal \lceil

Џلll Article views: 133

Q View related articles $\widetilde{ }$

View Crossmark data $\asymp$ 


\title{
A call for innovative social media research in the field of augmentative and alternative communication
}

\author{
Bronwyn Hemsley ${ }^{a *}$, Susan Balandin ${ }^{b}$, Stuart Palmer ${ }^{c}$ and Stephen Dann ${ }^{d}$ \\ ${ }^{\mathrm{a}}$ Faculty of Education and Arts, The University of Newcastle, Newcastle, NSW, Australia; ${ }^{\mathrm{b}}$ Faculty of Health, Deakin University, VIC, Australia; \\ ${ }^{C}$ Faculty of Science, Engineering and Built Environment, Deakin University, VIC, Australia; ${ }^{d}$ College of Business and Economics, Australian \\ National University, Canberra, ACT, Australia
}

\begin{abstract}
Augmentative and alternative communication (AAC) social media research is relatively new, and is built on a foundation of research on use of the Internet and social media by people with communication disabilities. Although the field is expanding to include a range of people who use AAC, there are limitations and gaps in research that will need to be addressed in order to keep pace with the rapid evolution of social media connectivity in assistive communication technologies. In this paper, we consider the aims, scope, and methodologies of AAC social media research, with a focus on social network sites. Lack of detailed attention to specific social network sites and little use of social media data limits the extent to which findings can be confirmed. Increased use of social media data across a range of platforms, including Instagram and YouTube, would provide important insights into the lives of people who use AAC and the ways in which they and their supporters use social media. New directions for AAC social media research are presented in line with those discussed at the social media research symposium at the International Society for Augmentative and Alternative Communication in Toronto, Canada, on August 12, 2016.
\end{abstract}

\section{ARTICLE HISTORY}

Received 4 October 2016

Revised 10 December 2016

Accepted 13 December 2016

\section{KEYWORDS}

Social media data; social network sites; augmentative and alternative

communication; AAC social media research; innovation

\section{Introduction}

In recent years, the research field of augmentative and alternative communication (AAC) and social media has expanded to include social media use by adolescents and adults who use AAC. Maintaining momentum and innovation in $A A C$ social media research is important for keeping pace with both AAC and social media developments, particularly in the context of AAC systems that enable users to post messages created on AAC systems direct to social network sites (e.g., AssistiveWare, 2013 ${ }^{1}$; Therapy Box, 2016²). boyd and Ellison (2007, p. 211) defined social network sites as:

\section{web-based services that allow individuals to (1) construct a public or semi-public profile within a bounded system, (2) articulate a list of other users with whom they share a connection, and (3) view and traverse their list of connections and those made by others within the system.}

Social network technologies are also designed to support persistence, visibility, spreadability, and searchability of materials published online (boyd, 2014). They may be particularly important for young people who use AAC in their search for greater inclusion. Indeed, Greenhow and Robelia (2009, p. 1135) postulated that:

the various processes of reading, writing, and appropriating digital materials to craft one's online self presentation may allow young people who have felt marginalized, the opportunity not only to reflect and transform the way they think of themselves, but also to communicate who they want to be to a mass audience, an opportunity previously afforded only to the privileged, and so extend the reach of their own influence.

Consequently, using social network sites could support people who use AAC to (a) become more persistent in engagement online, (b) become more visible and influential online, (c) grow the audience that they want to reach online, and (d) know how to find online connections that work for them, including locating employment and social opportunities. Hereon we use the term social media to refer to the use of popular social network sites (e.g., Facebook, ${ }^{3}$ Twitter, $^{4}$ Instagram, ${ }^{5}$ WhatsApp ${ }^{6}$ ). This reflects the use of the term social media as it appears in AAC literature.

Aiming to stimulate growth and innovation in the scope and methods of social media research in the field of AAC, a research symposium on the topic was held on August 12, 2016, as part of the research symposium of the Biennial International Society for Augmentative and Alternative Communication (ISAAC) held in Toronto, Canada on August 12 and 13, 2016. The social media research symposium was attended by 18 delegates and included three small discussion groups each focused on the targeted areas included in the program: (a) social media and publicity, privacy, and safety ( $n=5$, including the first author as moderator), (b) social media and romantic relationships $(n=5)$, and (c) social

CONTACT Bronwyn Hemsley bronwyn.hemsley@newcastle.edu.au @ @bronwynhemsley $\Theta$ School of Humanities and Social Science, Level 2, McMullin Building, University Drive, Callaghan NSW, Australia

*This article was edited by Martine Smith.

C) 2017 International Society for Augmentative and Alternative Communication 
media and acquired health conditions $(n=4)$ (Paterson, 2017). This forum paper relates to the first author's presentation at the symposium highlighting methodological aspects of AAC social media research to date, and the small group discussion on publicity, privacy, and safety in relation to AAC and social media research. The topics of the discussion emerged through the group's interaction, during which the first author took detailed notes that the group agreed reflected the outcomes of the discussion. In this paper, the outcomes of the small group discussion will be presented to inform a new agenda in the field of AAC social media research.

\section{An overview of AAC social media research}

\section{$A A C$ social media research in the broader context of communication disability}

The field of AAC social media research is relatively new, and has for the most part focused on children and youth with cerebral palsy. Although social media research to date has included a relatively small number of people who use $A A C$, it has provided valuable insights into social media use, particularly use of the popular social network sites Facebook and Twitter. Within the broader field of communication disability, there is a growing body of peer-reviewed research literature that includes (a) the use of virtual worlds (i.e., online computer-based environments designed to provide users with a shared simulation experience) of Second Life $^{7}$ by individuals with intellectual disabilities (Balandin \& Molka-Danielsen, 2015) and adults with autism spectrum disorder (ASD) (Stendahl \& Balandin, 2015), (b) the use of social media by adults with acquired communication impairments (Paterson \& Carpenter, 2015), (c) the use of Twitter by adults with traumatic brain injuries who have cognitive communication impairments (Brunner, Hemsley, Palmer, Dann, \& Togher, 2015) and adults with severe communication disabilities (Hemsley, Palmer, \& Balandin, 2014), and (d) the use of Facebook by adults with Williams syndrome (Lough \& Fisher, 2016). This literature emphasizes both the utility and importance of people with communication disabilities having access to social media and supports for using social media safely, as well as diversity in the broader field of communication disability and social media research to date.

Exploring the Internet use of young people with physical disabilities, Raghavendra, Wood, Newman, Lawry, and Sellwood (2010) surveyed 50 individuals and reported that all participants used the Internet "from over five hours a day to rarely/never for instant messaging, schoolwork, downloading music, using social networking sites (e.g., MySpace and Facebook) and other activities" (Raghavendra et al., 2010, p. 23). The findings of this small Australian study may well reflect the variation in Internet use in the general population but cannot be generalized to the current Internet use of young people who have communication impairments. Subsequently, 15 of the 50 young people surveyed were interviewed about their Internet use (Raghavendra, Wood, Newman, \& Lawry, 2012) but only three had complex communication needs, and only one used AAC. The authors reported that participants' friends played an important role in teaching them to use the Internet and interacting with them online, and that family resources and parental Internet skills were important in influencing the participants' use of the Internet.

AAC researchers have since reported outcomes of an intervention designed for children and young people with cerebral palsy living in metropolitan areas (Grace, Raghavendra, Newman, Wood, \& Connell, 2014; Raghavendra, Grace, Newman, Wood, \& Connell, 2013; Raghavendra, Newman, Grace, \& Wood, 2013) and rural areas (Raghavendra, Newman, Grace, \& Wood, 2015) to learn to use the Internet and social media. A majority of the metropolitan participants, recruited through the earlier survey of Raghavendra et al. (2010), "had minimal physical disability and good communication abilities" (Raghavendra, Grace, et al., 2013, p. 22.3; Raghavendra, Newman, et al., 2013, p. $39)$, and only five of the participants had complex communication needs. Raghavendra and colleagues concluded that the one-to-one intervention delivered at participants' homes was (a) effective in increasing performance and satisfaction in using the Internet for social participation, and (b) significantly increased the size of participants' social networks, as measured by the number of online communication partners (Raghavendra, Grace, et al., 2013; Raghavendra, Newman, et al., 2013), but (c) did not reduce participants' levels of loneliness (Grace, Raghavendra, Newman, Wood, \& Connell, 2014). Raghavendra et al. (2015) also reported outcomes of an intervention aimed to enhance the social participation of eight young people with communication disabilities - including individuals with cerebral palsy, autism spectrum disorder, and intellectual disabilities - who lived in rural Australia. Six of the participants communicated by speech and were intelligible to familiar partners, and only one participant used AAC (Key Word $\operatorname{Sign}^{8}$ ) as a primary mode of communication. The findings suggested that learning to use social media increased participants' social participation, and that in order for this to occur, both parents and service providers needed knowledge and skills to integrate assistive technology with the Internet. However, given the small sample size in the study it is not known to what extent the results could be applied to other young people who use AAC.

\section{Social media research involving people who use AAC}

In recent years, several studies that focused only on individuals who use AAC and social media have emerged. Three separate groups of researchers looked at social media use of 55 participants who included 46 with cerebral palsy (Caron \& Light, 2016a, 2016b; Hemsley, Dann, Palmer, Allan, \& Balandin, 2015; Hynan, Goldbart, \& Murray, 2015; Hynan, Murray, \& Goldbart, 2014), and 9 with amyotrophic lateral sclerosis (ALS) (Caron \& Light, 2015). Hynan and colleagues developed a grounded theory on the use of digital technology and online social media by 25 children and young adults with cerebral palsy aged 14-24 years (see Hynan et al., 2014, 2015). Supporting the earlier findings of Raghavendra and colleagues (Raghavendra et al., 2010; Raghavendra, Grace, 
et al., 2013; Raghavendra, Newman, et al., 2013), the core category of the grounded theory was that young people who use AAC want to use the Internet and social media, with eight supporting categories related to patterns of use, supports, challenges, technology, AAC, self-determination, self-representation, and social ties. Several of the quotes from participants referred to the use of Facebook. Despite anecdotal reports of the use of Facebook by very young children, research in the field of AAC has yet to focus on children at or below 13 years of age, the usual age required in terms of agreement when using social media sites. Children in the general population begin to use social media, notably Facebook, at a very young age, with a majority of children under the age of 13 using Facebook and/or Twitter (Livingstone Haddon, Görzig, \& Ólafsson, 2011). Although parents may be aware that their children have and use Facebook and/or other social media sites, it cannot be assumed that the platforms are being used with parental permission, supervision, or support, as children also report leaving the Facebook environment to use other social network sites (including Twitter, Instagram, Vine, ${ }^{9}$ and WhatsApp) in order to avoid parents' Facebook friend requests (Livingstone et al., 2011). This suggests that further research is needed in the field of AAC to determine at what age individuals who use AAC begin to use social media and how such use is managed by stakeholders including children and youth, their peers, and their parents. Further discussion of the ethical implications of AAC research including children under 13 who are using social media is also needed.

\section{Exploring specific social media platforms}

In order to provide more detail on participants' preferences for social network sites, and expanding the focus to include more adults who use AAC, Caron and colleagues (see Caron \& Light, 2015, 2016a, 2016b) used online focus groups methodology to examine the use of social media by people who use AAC, including adolescents and young adults with cerebral palsy $(n=7)$ who were aged 14-21 years with an average age of 18 , adults with cerebral palsy $(n=9)$, and adults with ALS $(n=9)$. Across these studies, all participants reported using Facebook $(n=25)$, and a majority $(n=16)$ reported using other social network sites such as Twitter, Instagram, Pinterest, ${ }^{10}$ Vine, or MySpace ${ }^{11}$ in various combinations. Facebook was the preferred social network site for all but two of the 25 participants, both of whom had ALS. Only two of the children and two of the adults with cerebral palsy used Twitter (Caron \& Light, 2016a, 2016b); however, two of the five adults with ALS who used Twitter reported that it was their preferred social network site (Caron \& Light, 2015). These findings suggest that, in order to develop a full appreciation of social media use of people who use AAC, the scope of AAC social media research needs to expand beyond Facebook to include all sites used. In particular, AAC social media research needs to include public social media sites such as Twitter and Instagram, where larger networks are made possible by the use of hashtags (i.e., \#hashtag hyperlinked social media posts) and where short messages and pictures or videos are used. The literacy demands and expectations for public social media and micro-blogging sites may differ from those associated with using Facebook, making these sites more attractive for people with limited literacy skills or those who fatigue easily when typing.

At the time of writing, Twitter was the only social media platform from which social media publications authored by people who use AAC have been harvested and analyzed using quantitative and qualitative methods (Hemsley et al., 2015). Hemsley et al. reported on a mixed-methods study of five adults with cerebral palsy who used AAC, and analyzed both social media data and in-depth interviews using narrative inquiry. Four of the five participants demonstrated early in their use of Twitter that they were using the platform to have conversations with familiar and unfamiliar communication partners, share links, and communicate with the much larger macro Twitter audience (i.e., public, not relying on "follower-followee" networks) by using hashtags strategically. The participants' Twitter data networks also reflected that they formed a networked community on the Twitter platform. One participant preferred to use Facebook as an expressive mode of communication, and only used Twitter to read and follow posts written by other Twitter users. Another participant used Twitter strategically as an adjunct to Facebook and Instagram by tweeting links across platforms and using hashtags to reach a larger audience. These findings suggest that people who use AAC are able to find connections within and beyond communities who use $A A C$, and that Twitter is a useful platform to read and to listen to others even if people do not use it as an expressive mode of communication. To date, there are no studies exploring the use of Twitter by children and young people who use AAC.

\section{Hashtag studies}

Hashtag research is possible in both Twitter and Instagram, as both platforms enable retrieval of posts that include a particular hashtag. To date, in relation to AAC and social media, only hashtag studies of Twitter use by people with ALS (Hemsley \& Palmer, 2016; Hemsley, Palmer, Goonan, \& Dann, 2017) and traumatic brain injuries (TBI) (Brunner, Hemsley, Togher, Dann, \& Palmer, 2017) have been reported. Recognizing the large community in Twitter now tweeting about ALS (Koohy \& Koohy, 2014), and the previously narrow scope of ALS Twitter research that focused on fundraising, Hemsley and Palmer (2016) collected 4625 public tweets tagged from a Twitter user with ALS who used AAC, and another 4625 publicly available tweets tagged with \#ALS or \#MND, for qualitative and quantitative analysis (Palmer, 2014). Ethical approval and informed consent were obtained for both collecting the tweets of an adult with ALS who relied on $A A C$ and conducting an in-depth interview with this individual about the tweets. However, the interview was abandoned due to the participant's time and energy constraints (Hemsley \& Palmer, 2016). Across both sets of public tweets' data, the analysis of status broadcast tweets (i.e., that reflect user experience, activity, views) and conversational tweets (i.e., that mention or reply to another user) revealed that the Twitter platform was used for conversational 
interaction on a wide variety of topics, including self-advocacy, raising awareness of ALS, and engaging with service providers on accessibility issues (Hemsley \& Palmer, 2016). In a follow-up hashtag study on ALS-related tweets, Hemsley et al., 2017) analyzed 3288 tweets and reported poignant reflections on the daily life of people with ALS and their families, not only in the content written on tweets but also in the addition of poetic hashtags (e.g., \#lvegrownaccustomedtoALS). Such Twitter hashtag research methods could be applied to other conditions associated with complex communication needs (e.g., using tags \#TraumaticBrainlnjury \#TBI \#CerebralPalsy or \#CP) for insights into the daily life of tweeters who disclose having these conditions. Indeed, Brunner and colleagues used hashtag research methodology to examine the use of Twitter by people with cognitive communication impairments associated with traumatic brain injury (TBI) (Brunner et al., 2017). The content of conversational and status broadcast tweets reflected Twitter being used to discuss and share TBI-related health information; raise awareness of TBI-related issues including causes, symptoms, and associated disability; and provide insight into the lived experience of having a traumatic brain injury. Thus, further hashtag studies in Twitter or Instagram could provide abundant data yielding useful insights into the needs and experiences of people who use AAC.

\section{Gaps and limitations in AAC social media research}

The small group discussion at the ISAAC research symposium examined the findings of social media research in the field of $A A C$, gaps and limitations in the research, and topics worthy of further research. The group agreed that, to date, social media research has involved (a) online data collection (e.g., online discussion boards and blogs) to gather people's views on social media, (b) traditional quantitative and qualitative methods (e.g., pre-post intervention designs; surveys, indepth or semi-structured interviews) to determine the impact of training in social media and people's views and experiences of using social media, and (c) analysis of publicly available social media data of people who use AAC to investigate their social media use combined with interviews on participants' views of the data and experiences of the platform. The group agreed that all of these research techniques could be applied to a wider range of social network sites and used in combination. Future research could include a greater number of people who use AAC in order to gain important insights into their social media worlds, which in turn may inform supports to increase use of social media, reduce isolation, and provide better channels for online information exchange.

\section{Lack of attention to data collected from social network sites}

To date, the majority of AAC research on social media has been exploratory in nature, asking people about the social media platforms that they use and prefer, and their views and experiences of the various platforms. Although Facebook is often reported as a preferred social network site (Hynan et al., 2014, 2015; Caron \& Light, 2015, 2016a, 2016b), there are no studies reporting on the analysis of Facebook text, pictures, or multimedia data posted by people who use AAC. The lack of attention to this data (e.g., number and content of posts, social media behaviors, cyber safety, management of personal control settings, and group membership) represents a significant gap in AAC research. Reliance only on people's perceptions of social media use may miss important insights that can be gained by gathering and analyzing their social media data, which also demands taking the architecture of the social network site into account (e.g., the ways that Facebook suggests contacts to follow or groups to join; or that Twitter suggests people or entities to follow). Harvesting, cleaning (i.e., removing duplicates, spam posts, or repeated posts as desired), and analyzing the social media data of people who use AAC would help to verify participants' reports of social media knowledge or use of the platforms. In addition, analysis of social media posts might facilitate easier participation in research, overcoming some of the barriers of face-to-face research (e.g., adults with ALS, Hemsley et al., 2017), because the collection of social media data for AAC research poses no additional effort for the participants (Hemsley \& Palmer, et al., 2016). Increasing the scope of research and applying a wider range of social media research methodologies would potentially yield new insights into the use of social media by people who use AAC; and could also be used to triangulate, verify, and expand upon participants' reports of their views and experiences of social media platforms.

\section{The strategic use or management of multiple social network sites}

Although it is usual for people in the community-at-large to use multiple social media platforms and develop multiple literacies to support these activities (Greenhow \& Robelia, 2009), there is little information available on the use of multiple social media platforms by people who use AAC, or how their social media accounts might be used in strategic combinations or separated for particular purposes (e.g., public and/or private, professional and/or personal). In addition, there are no reports in the literature of (a) AAC research focusing on the popular visual format platforms Instagram, which uses pictures posted online, or YouTube, ${ }^{12}$ which uses multimedia video and/or audio tracks, or (b) Twitter research including children and youth aged 13 years and over, as the platform allows registration by this group. Investigating all of the social media platforms used by people who use AAC, and the ages at which they start to use and move on to different platforms, could provide important insights into (a) how AAC online communities are established and developed, (b) changes in social media use over life stages, (c) how linkages across a diverse range of platforms help to engage new members to these communities, and (d) how people who use AAC move between the different social network sites and respond to the different 
challenges each one presents or the additional challenges associated with using multiple social network sites.

\section{Narrowed aims and scope of the research}

There are important limitations in research on social media and AAC to date. Beyond increasing the numbers of people who use AAC in social media research, the aims and scope of social media research in the field of AAC need to expand in order to examine the broader purposes of using social network sites (boyd, 2014; boyd \& Ellison, 2007; Greenhow \& Robelia, 2009). People who use AAC are a marginalized population who might benefit from a greater understanding of how social media might be used in emancipatory and participatory action research, and in relation to on-line self-promotion and self-advocacy (Greenhow \& Robelia, 2009). Although attention to social media platforms in general (i.e., across platforms of different types) could provide insight into the principles that users apply across multiple platforms, it may miss important differences between platforms, and provide little detail in terms of function, purpose, audience, and operation of each. It may also fail to differentiate the risks and benefits of using multiple social media platforms.

\section{Expanding the scope of AAC research to focus on issues affecting social media safety}

Potential topics for research related to social media and people who use AAC were discussed during the research symposium, and the outcomes are presented in six non-mutually exclusive and related categories in Table 1: (a) Legal issues: publicity/privacy, (b) Legal issues: publishing, (c) Ethical issues: conduct of social media research, (d) Ethical issues: autonomy and personal control, (e) Social media skills, and (f) Social media safety. The group acknowledged the complexity of AAC social media research, noting that each of the categories impacted the others, owing to the public nature of social media data and the involvement of supporters in relation to Internet use by people who use AAC. The list of relevant research questions provided in Table 1 is not intended to be either limiting or comprehensive, and is not in any particular order of priority or importance. Rather, the relevant research questions suggested for each category are informed by clinical and research anecdotes shared within the group discussion and the findings of recent AAC social media research. Further discussion would be needed with people who use AAC and support organizations to set research priorities that are person-centred and that potentially have impact across the categories and across multiple social media platforms.

\section{Legal issues, ethical issues, and social media skills}

The items discussed in the social media symposium and presented in Table 1 reflected that the field of AAC social media research is at an early stage, particularly in considering the issues arising with respect to publicity and privacy in social media combined with participation in AAC research. The group discussion supported the notion that participating in social media involves understanding and acting on both rights and responsibilities in a digitally connected community (Roger, 2014). However, there is little information available about whether or not people with complex communication needs or their supporters know their rights, recognize the risks and how to respond, or fulfil their responsibilities when using the Internet or multiple social media platforms. It should be noted that there are many users of social media without disabilities who are also unaware of these issues. With regard to the safe use of social media by children, the views of the discussants related primarily related to the management of public or private social media self-publishing, in relation to not only risks but also benefits, particularly in terms of raising awareness and improving positive attitudes towards people who use AAC.

Research to date reflects that people with complex communication needs require increased access and opportunities for participation and inclusion online. However, parents, friends, and paid direct support workers often function as gatekeepers for access to the computer and Internet (Balandin \& MolkaDanielsen, 2015; Raghavendra et al., 2012). Although many people with disabilities rely on another person to access a computer and the Internet on their behalf (Raghavendra et al., 2012), it is not known how many also rely on proxy users to use social media on their behalf (see Selwyn, Johnson, Norman, \& Wright, 2016). Reliance on third parties to use social media places adults who use AAC at risk of over-protection and exclusion from online communities (Stendahl \& Balandin, 2015). This, in turn, prevents these individuals from learning to use social media and the benefits it offers, and reduces opportunities to develop cyber-resilience as part of the learning process (Balandin \& Molka-Danielsen, 2015).

Social media platforms are used across the world to give people a voice in wider society; yet people with disabilities are under-represented in social media (Media Access Australia, 2012). It is important to encourage more people with communication disabilities to use social media for selfexpression (Hemsley et al., 2015; Raghavendra et al., 2012), and to urge professionals who support adults who use AAC to also become more familiar with and competent in using social media (Caron \& Light, 2015, 2016a, 2016b; Hemsley \& Bowen, 2014; Hemsley et al., 2015). At the same time, it is also important to identify any potential harms associated with social media use and to identify effective supports, training, or other resources required to mitigate the risks (Raghavendra, Grace, et al., 2013; Raghavendra et al., 2015).

\section{Safety issues}

To date, there are no reports of research examining the effect of implementing safeguards for social media cybersecurity for people who use AAC, and research on social media in the broader field of communication disability has not provided information on ways for people to respond to or recover from these risks, to build cyber-resilience (Australian Securities and Investments Commission [ASIC], 2015). People who use AAC may be at increased risk of cyber-security incidents (e.g., threats to privacy, reputation, 
Table 1. Group outcomes: key focus areas and research questions for future AAC social media research.

Key focus area

Legal issues: Social media publishing

Ethical issues: Conduct of social media AAC research

Ethical issues: Autonomy and personal control

Social media skills

Safety issues
Relevant research questions

Is social media used to raise public awareness and what is the impact of this?

How are people who use AAC using podcast/Twitter/blogs for communication, information exchange, or social closeness?

How do people who use AAC manage the timing and strategy of sharing information, including by proxy users, within and across platforms?

Does self-publishing increase control of the person's own message?

Does the use of social media increase meaningful participation and inclusion? (e.g., becoming visible/having an audience/being heard/hiding or showing disability/avoiding negative stereotyping and exclusion)

How is social media used as a form of self-advocacy?

Are people who use AAC and their supporters aware of the implications of ownership of intellectual property, storage or licensing of material posted on social media sites, either as a producer or publisher in social media, and as outlined in the terms of service agreements?

How do people who use AAC and their service providers act to protect intellectual property and commercial interests in social media publications?

What public and private social media publications can be collected in ethical AAC research?

In what circumstances might informed consent be required, obtained, or waived in very large datasets of publicly available data?

What is the influence on gatekeepers in preventing or facilitating the inclusion of people who use AAC in social media research?

What are the ethical implications of direct recruitment of people who use AAC through social media recruitment methods?

How should public and private social media publications be reported in small communities of people who use AAC?

What influences the identification or de-identification of social media posts authored by people who use AAC?

What are the legal and ethical issues relating to the use of social media data published by young children who use AAC?

How do people who use AAC manage communication with multiple audiences, including management of publicity and privacy using the personal controls on different social network sites?

How do people who use AAC manage open (public) and closed (private or semi-private) groups on social network sites?

What are the perceptions of people who use AAC on privacy or pseudo-privacy on social media platforms?

What factors explain the phenomena of trust development or breach of trust (e.g., in relation to onward sharing) on social media platforms by people who use AAC?

How do people who use AAC work within the limitations of social media platforms (e.g., limits of text, use of emoticons)?

What supports people who use AAC to develop skills, competencies, and confidence in using computers, the Internet, and social media, including cultural practices in online interactions?

Do researchers in the field of AAC need to be competent and confident in use of the social media being researched? How does the expertise of the researcher impact on the data collected (e.g., by technical knowledge, experience, and cultural awareness of the social network site used)?

Over time, does the social media data of people who use AAC reflect development from novice to experienced social media users?

What are the cultural practices and languages of social media communities including people who use AAC?

What supports people who use AAC to develop and maintain an awareness of the needs and demands of each intended audience in different social media platforms?

What are the roles and skills of support workers and family members of people who use $A A C$, in using social media as a proxy for the person who uses AAC?

Does reading and writing in social media increase opportunities for literacy instruction or impact on literacy for people who use AAC?

How do people who use AAC combine linguistic (text-based) social media (e.g., Twitter), and non-linguistic (picture-based) social media (e.g., Instagram)?

Does reliance on other people to support or access use of social media impact on risks to safety using social media?

What threats to cyber-safety are experienced?

How do people who use AAC develop cyber-resilience?

What is the impact of social media on safety in the real world?

How do risks of negative impacts change as social media platforms change?

Do adolescents have adequate opportunities to learn how to manage the risks of social media?

How do individuals in groups online experience risks and protections in social media?

What degrees of protection are afforded to people who use AAC?

Is there an additional risk of denial of opportunity to use social media? 
and financial security; hacking; impersonation; identity theft; cyber bullying), due to (a) the person's communication impairment (e.g., comprehension difficulties; Hemsley et al., 2015), (b) behaviors associated with the person's disability (e.g., increased acquiescence, limited ability to weigh the consequences of a range of actions; Lough \& Fisher, 2016), (c) low levels of literacy (Sturm et al., 2006), and (d) reliance on third parties (family, friends) for access to the Internet, social media, and security controls (Stendahl \& Balandin, 2015; Raghavendra et al., 2012). Hemsley and Dann (2014) also noted that potential harms in social media can include exposure to unreliable information, and that certain protections are needed to fortify individuals with communication disabilities and their families against misinformation (incorrect information) and disinformation (deliberately deceptive information) in social media.

\section{The Causal Chain Framework For Social Media Research}

In the absence of research exploring social media safety in the field of $A A C$, it is not clear how people who use AAC develop or navigate risk-based decision-making in regards to the use of social media, and what strategies would support them to use social media safely and enable them to respond to and recover from adverse events. Identifying common risk behaviors related to interpersonal cyber-security vulnerability between people who use AAC and their family members or direct support workers would help inform the full range of reasonable and necessary supports and associated safeguards required and associated costs. The Causal-Chain Framework for Social Media Research (Ngai, Tao, \& Moon, 2015) could be used to guide research into social media safety for people who use AAC. This framework conceptualizes the interaction of antecedents of social media behavior (user experiences and perceptions, social and organizational factors), with mediators (platform attributes, social factors, user attributes), and moderators of social media behaviour and how in combination these factors influence social media safety outcomes (Ngai, Tao, \& Moon, 2015). The Framework aligns well with models of disability such as the International Classification of Functioning, Disability, and Health (World Health Organization, 2001) which recognize that individual factors interact with factors in the environment and activities to influence disability outcomes.

The Causal Chain Framework for Social Media Research is also complementary to the cyber-resilience framework proposed by the Australian Securities and Investments Commission (ASIC, 2015). According to ASIC (2015), the interaction of several factors (e.g., governance, information, assets, awareness, knowledge, risks, and monitoring) - in both organizations (e.g., service providers, employers) and individuals - are critical to identify, protect, detect, respond, and recover from threats to safety (ASIC, 2015; Ngai et al., 2015). The privacy, security, and cyber-resilience of people who use AAC and their families and direct support workers is worthy of further attention in future AAC research, particularly to (a) identify potential risk areas arising in relation to integrating social media technology with AAC systems (e.g., using the $A A C$ system to send messages or pictures to a social media platform), (b) identify the roles, responsibilities, and needs of direct support workers and balance these with individual rights of persons who use $A A C$, and (c) understand contributing or causal factors in social media safety for people who use AAC. Critical analyses of social media safety incidents could yield information on factors contributing to harmful safety incidents, inform actions being taken to reduce the risk of safety incidents, enhance the safe use of social media, and support the autonomy and self-determination of adults with communication disability. Intervention studies on behavioral and attitudinal interventions and social change campaigns could be used to enhance audience knowledge of appropriate or safe social media conduct (Dann, 2010). Understanding current perceptions of safety and risk could inform improved knowledge, awareness, and attitudes to support harm reduction and the safe use of social media for more people who use AAC. Evidence relating to this is needed to develop appropriate policies and procedures on teaching or supporting people who use AAC to use social media.

\section{Conclusions}

Researchers building on the foundations of social media and $A A C$ research to date will need to implement a wider range of social media data collection and analysis methods that make use of social media data, and attend to diverse and multiple social media platforms, if the directions for new research outlined in this paper are to be realized. A focus on safety and cyber-resilience across social media platforms will also be important. This could help to inform development of interventions that fortify individuals who use AAC and their supporters against preventable and harmful social media safety incidents, and possibly reduce gatekeeping activities that are now utilized to prevent people who use AAC from accessing social media in the same way as their peers without disabilities.

\section{Notes}

1. AssistiveWare B.V., Laurierstraat 193, 1016 PL, Amsterdam, Netherlands. www.assistiveware.com

2. Therapy Box Limited, 505 Pinner Road, North Harrow, Middlesex, HA2 6EH, UK. www.therapy-box.co.uk

3. Facebook HQ, 1 Hacker Way, Menlo Park, California, 94025, USA. www. facebook.com

4. Twitter Headquarters, 1355 Market Street, Suite 900, San Francisco, California, 94103, USA. www.twitter.com

5. Instagram HQ, 181 South Park Street, Suite 2, San Francisco, California, 94107, USA. www.instagram.com

6. WhatsApp. WhatsApp Inc. 650 Castro Street, Suite 120-219, Mountain View, California, 94041, USA. www.whatsapp.com

7. Second Life, Linden Lab Headquarters. 945 Battery Street, San Francisco, California, 94111, USA. https://secondlife.com/

8. Key Word Sign Australia, 830 Whitehorse Road, Box Hill, Victoria, 3128, Australia. www.scopeaust.or.au/key-word-sign-australia/

9. Vine Labs Inc., 51 East 12th Street, 10th Floor, New York, New York, 10003, USA. https://vine.co/

10. Pinterest Corporate Office, 808 Brannan Street, San Francisco, California, 94103, USA www.pinterest.com

11. MySpace LLC, 8391 Beverly Boulevard, Suite 349, Los Angeles, California, 90048, USA. https://myspace.com/

12. YouTube, LLC, 901 Cherry Avenue, San Bruno, California, 94066, USA www.youtube.com 


\section{Acknowledgements}

The authors would like to thank and acknowledge members of the small discussion group at the social media research symposium of the International Society for Augmentative and Alternative Communication Research Symposium held in Toronto, Canada on August 12, 2016.

\section{Funding}

This work was supported in part by a Discovery Early Career Research Award to the first author from the Australian Research Council.

\section{References}

Australian Securities and Investments Commission (ASIC). (2015). Report 429, Cyber-resilience Health Check. Australian Securities and Investments Commission. Retrieved from http://asic.gov.au/regulatoryresources/find-a-document/reports/rep-429-cyber-resilience-healthcheck/

AssistiveWare. (2013). AssistiveWare reveals Proloquo2Go 3.0 with ExpressivePower, switch access, social sharing, new voices and Dropbox support. AssistiveWare. Retrieved from http://www.assistiveware.com/ assistiveware-reveals-proloquo2go-30-expressivepower-switch-accesssocial-sharing-new-voices-and

Balandin, S., \& Molka-Danielsen, J. (2015). Teachers' perceptions of virtual worlds as a medium for social inclusion for adults with intellectual disability. Disability and Rehabilitation, 37, 1543-1550. doi:10.3109/ 09638288.2015.1052574

boyd, D. (2014). It's complicated: The social life of networked teens. London: Yale University Press.

boyd, D., \& Ellison, N.B. (2007). Social network sites: Definition, history, and scholarship. Journal of Computer-Mediated Communication, 13, 210-230. doi:10.1111/j.1083-6101.2007.00393.x

Brunner, M., Hemsley, B., Palmer, S., Dann, S., \& Togher, L. (2015). Review of the literature on the use of social media by people with traumatic brain injury (TBI). Disability and Rehabilitation, 37, 1511-1521. doi:10. 3109/09638288.2015.1045992

Brunner, M., Hemsley, B., Togher, L., Dann, S., \& Palmer, S. (2017). Hashtag TBI: How do traumatic brain injury communities communicate and network in Twitter? Paper accepted to the International Cognitive-Communication Disorders Conference, January 19-21, 2017, Chapman University, Orange, CA.

Caron, J., \& Light, J. (2015). "My world has expanded even though I'm stuck at home": Experiences of individuals with amyotrophic lateral sclerosis who use augmentative and alternative communication and social media. American Journal of Speech-Language Pathology, 24, 680-695. doi:10.1044/2015_AJSLP-15-0010

Caron, J., \& Light, J. (2016a). Social media has opened a world of open communication: Experiences of adults with cerebral palsy who use augmentative and alternative communication and social media. Augmentative and Alternative Communication, 32, 25-40. doi:10.3109/ 07434618.2015 .1052887

Caron, J.G., \& Light, J. (2016b). Social media experiences of adolescents and young adults with cerebral palsy who use augmentative and alternative communication. International Journal of Speech-Language Pathology, Advance online publication. doi:10.3109/17549507.2016. 1143970

Dann, S. (2010). Redefining social marketing with contemporary commercial marketing definitions. Journal of Business Research, 63, 147-153. doi:10.1016/j.jbusres.2009.02.013

Grace, E., Raghavendra, P., Newman, L., Wood, D., \& Connell, T. (2014). Learning to use the Internet and online social media: What is the effectiveness of home-based intervention for youth with complex communication needs? Child Language Teaching and Therapy, 30, 141-157. doi:10.1177/0265659013518565

Greenhow, C., \& Robelia, B. (2009). Old communication, new literacies: Social network sites as social learning resources. Journal of ComputerMediated Communication, 14, 1130-1161. doi:10.1111/j.1083-6101. 2009.01484.x
Hemsley, B., \& Bowen, C. (2014). A call for evidence to inform the use of Twitter in speech language pathology. Journal of the SpeechLanguage-Hearing Association of Taiwan, 33, 61-72.

Hemsley, B., \& Dann, S. (2014). Social media and social marketing in relation to facilitated communication: Harnessing the affordances of social media for knowledge translation. Evidence-Based Communication Assessment and Intervention, 8, 187-206. doi:10.1080/17489539.2015. 1023988

Hemsley, B., Dann, S., Palmer, S., Allan, M., \& Balandin, S. (2015). "We definitely need an audience": Experiences of Twitter, Twitter networks and tweet content in adults with severe communication disabilities who use augmentative and alternative communication (AAC). Disability and Rehabilitation, 37, 1531-1542. doi:10.3109/09638288.2015.1045990

Hemsley, B., \& Palmer, S. (2016). Two studies on Twitter networks and tweet content in relation to amyotrophic lateral sclerosis (ALS): conversation, information, and 'diary of a daily life'. Studies in Health Technology and Informatics, 227, 41-47. doi:10.3233/978-1-61499-666-8-41

Hemsley, B., Palmer, S., \& Balandin, S. (2014). Tweet reach: A research protocol for using Twitter to increase information exchange in people with communication disabilities. Developmental Neurorehabilitation, 17, 84-89. doi:10.3109/17518423.2013.861529

Hemsley, B., Palmer, S., Goonan, W., \& Dann, S. (2017). Motor Neurone Disease (MND) and Amyotrophic Lateral Sclerosis (ALS): Social media communication on selected \#MND and \#ALS tagged tweets. Proceedings of the 50th Annual Hawaii International Conference on System Sciences (HICSS), January 4-7, 2017. pp. 3765-3733. Retrieved from https://scholarspace.manoa.hawaii.edu/handle/10125/41613

Hynan, A., Goldbart, J., \& Murray, J. (2015). A grounded theory of Internet and social media use by young people who use augmentative and alternative communication (AAC). Disability and Rehabilitation, 37, 1559-1575. doi:10.3109/09638288.2015.2056387

Hynan, A., Murray, J., \& Goldbart, J. (2014). "Happy and excited": Perceptions of using digital technology and social media by young people who use augmentative and alternative communication. Child Language and Teaching Therapy, 30, 175-186. doi:10.1177/ 0265659013519258

Koohy, H., \& Koohy, B. (2014). A lesson from the ice bucket challenge: Using social networks to publicize science. Frontiers in Genetics, 5, 430. doi:10.3389/fgene.2014.00430

Livingstone, S., Haddon, L., Görzig, A., \& Ólafsson, K. (2011). EU Kids Online: Final Report 2011. Retrieved from http://www.lse.ac.uk/collections/EUKidsOnline/

Lough, E., \& Fisher, M.H. (2016). Internet use and online safety in adults with Williams syndrome. Journal of Intellectual Disability Research, 60, 1020-1030. doi:10.1111/jir.12281

Media Access Australia (2012). Sociability: Social Media for People with a Disability. Australia: Media Access. Retrieved from http://www. mediaaccess.org.au/web/social-media-for-people-with-a-disability

Ngai, E.W.T., Tao, S.S.C., \& Moon, K.K.L. (2015). Social media research: Theories, constructs, and conceptual frameworks. International Journal of Information Management, 35, 33-44. doi:10.1016/j.jijnfomgt.2014.09.004

Palmer, S. (2014). Characterizing university library use of social media: A case study of Twitter and Facebook from Australia. The Journal of Academic Librarianship, 40, 611-619. doi:10.1016/j.acalib.2014.08.007

Paterson, H. (2017). The use of social media by adults with acquired conditions who use AAC: current gaps and considerations in research. Augmentative and Alternative Communication (in press).

Paterson, H., \& Carpenter, C. (2015). Using different methods to communicate: How adults with severe acquired communication difficulties make decisions about the communication methods they use and how they experience them. Disability and Rehabilitation, 37, 1522-1530. doi:10.3109/09638288.2015.1052575

Raghavendra, P., Grace, E., Newman, L., Wood, D., \& Connell, T. (2013). "They think I'm really cool and nice": The impact of Internet support on the social networks and loneliness of young people with disabilities. Telecommunications Journal of Australia, 63, 22-21.

Raghavendra, P., Newman, L., Grace, E., \& Wood, D. (2013). "I could never do that before": Effectiveness of a tailored Internet support intervention to increase the social participation of youth with disabilities. 
Child: Care, Health, and Development, 39, 552-561. doi:10.1111/cch. 12048

Raghavendra, P., Newman, L., Grace, E., \& Wood, D. (2015). Enhancing social participation in young people with communication disabilities living in rural Australia: Outcomes of a home-based intervention for using social media. Disability and Rehabilitation, 37, 1596-1590. doi:10.3109/09638288.2015.1052578

Raghavendra, P., Wood, D., Newman, L., \& Lawry, J. (2012). "Why aren't you on Facebook"? Patterns and experiences of using the Internet among young adults with physical disabilities. Technology and Disability, 24, 149-162. doi:10.1111/cch.12048

Raghavendra, P., Wood, D., Newman, L., Lawry, J., \& Sellwood, D. (2010). How are children and adolescents with physical disabilities using the Internet? Implications for social networking. Developmental Medicine and Child Neurology, 52, 23.

Roger, C. (2014). Privacy and social media: An analytical framework. Journal of Law, Information and Society, 8, 23. Retrieved from http://www.austlii.edu.au/au/journals/JILawInfoSci/2014/8.html
Selwyn, N., Johnson, N., Norman, S., \& Wright, E. (2016). Going Online on Behalf of Others: An Investigation of 'proxy' Internet Consumers. Sydney: Australian Communications Consumer Action Network. Retrieved from https://accan.org.au/files/Grants/ACCAN_Monash_2016_Going\%20 online\%20on\%20behalf\%20of\%20others_WEB.pdf

Stendahl, K., \& Balandin, S. (2015). Virtual worlds for people with autism spectrum disorder: A case study in Second Life. Disability and Rehabilitation, 37, 1591-1598. doi:10.3109/09638288.2015.1052577

Sturm, J.M., Spadorcia, S.A., Cunningham, J.W., Cali, K.S., Staples, A., Erickson, K., ..., Koppenhaver, D.A. (2006). What happens to reading between first and third grade? Implications for students who use AAC. Augmentative and Alternative Communication, 22, 21-36. doi:10. 1080/07434610500243826

Therapy Box. (2016). Predictable user guide version 4.1. Retrieved from https://therapy-box.co.uk/docs/userguide english\%203.3.pdf

World Health Organization. (2001). International Classification of Functioning, Disability, and Health. World Health Organization. Retrieved from http://www.who.int/classifications/icf/en/ 